\title{
Genetic Algorithm and Hybrid Genetic Algorithm for Space Allocation Problems- A Review
}

\author{
Jyoti Sharma \\ Department of Computer \\ Science and Engineering \\ Krishna Institute of Engineering \\ and Technology \\ Muradnagar (Ghaziabad)
}

\author{
Ravi Shankar Singhal \\ Department of Computer \\ Science and Engineering \\ Krishna Institute of Engineering \\ and Technology \\ Muradnagar (Ghaziabad)
}

\begin{abstract}
Genetic algorithm is an evolutionary approach for solving space layout and optimization problems. Due to some drawbacks in genetic algorithm, several modifications are performed on this algorithm. When the advantages of GA are combined with advantages of another algorithm then this approach is called Hybrid Genetic Algorithm. One of the most difficult problems in architectural design is space layout problem. Various methods are proposed for solving this problem like hybrid genetic algorithm, fuzzy logic, and artificial neural network. Space layout problem commonly occurs in warehouse, hotel, building floors, containers, shelves etc. Present paper contains a review on genetic algorithm, hybrid genetic algorithm approaches for solving space allocation problems on different sample test like warehouse, shelf, building floors and container etc. A comparison has been done of twelve research paper. The findings of this paper will be useful for those who look for solution of space allocation problem on different models.
\end{abstract}

\section{Keywords}

Genetic algorithm, Hybrid genetic algorithm, Space allocation problems..

\section{INTRODUCTION}

The genetic algorithm (GA) is a soft computing technique which is used for optimization and search. It is based on natural selection and genetics principles [1]. Optimization concerns with finding the best solution among all possible solution which satisfy all the constraints. With some advantages, GA has also some drawbacks: slow rate of convergence, huge calculations for generations and populations etc. some modifications are needed to overcome these drawbacks and improve the performance of GA. Traditional optimization algorithm needs a better set of initial values for the design variables. If they found it, they will converge rapidly to generate good results. The problem is only the long trial and error process in finding initial values. To overcome these difficulties, a hybrid approach is presented using GA and traditional algorithms [2].

Space allocation concerns with finding feasible space for objects such as products in warehouse, rooms on a floor, product in container, which meet design requirement and maximize design quality. Present paper represents a review on two approaches genetic algorithm and hybrid genetic algorithm for solving space allocation and layout problems.
This paper is divided into 5 sections. In second section, we introduce the basics of genetic algorithm, hybrid genetic algorithm and its application for space layout and allocation problems. In third section the literature review of all the work done on this problem is summarized. In fourth section a comparison sheet of 12 research papers is discussed. In last section conclusion is provided.

\section{GENETIC ALGORITHM AND HYBRID GENETIC ALGORITHM}

John Holland was first to describe the concept of genetic algorithm in 1960s. It is further explored by Holland's students and colleagues in 1960 and 1970. [3]. It is based on natural evolution and used to solve search and optimization problems. It is based on Charles Darwin's theory of "survival of the fittest". The input of this algorithm is set of possible solutions of the problem. A fitness value is assigned to each solution or individual which denotes how good a solution is. For example we can take the final report of students in any school. If student's performance is good in examination then his final report will be good and he will be promoted to next class. On the other hand those, who have bad marks and worst report, will not be promoted to next class. Similarly in case of genetic algorithm, the individual with good fitness value will reproduce next population and the least fit members have fewer chances to be selected for reproduction [4].

Each solution in search space is represented by chromosomes and each chromosome represented by string of bits (string of 1 's and 0's). There are three operators in GA which are used to generate new population from parent population: selection, crossover, mutation. Selection operator selects chromosomes for production based on its fitness value. Highly fitted chromosomes are more times likely to be selected than less fitted ones. A simple genetic algorithm and its applications are described in [1] [3] and [4]. Table 1 represent advantages and disadvantages of genetic algorithm which are described in [1] [2] and [5].

With some advantages, GA has also some drawbacks. A new hybrid optimization technique is proposed which combines GA with traditional optimization procedures to remove the drawbacks and improve the performance of GA. GA is global search method. When GA is combined with any 
Table: 1 Advantages and disadvantages of GA

\begin{tabular}{|l|l|}
\hline \multicolumn{1}{|c|}{ Advantages } & \multicolumn{1}{c|}{ Disadvantages } \\
\hline $\begin{array}{l}\text { 1. Optimize with continues } \\
\text { and discrete variables. }\end{array}$ & $\begin{array}{l}\text { 1. Rate of convergence is not } \\
\text { so good. }\end{array}$ \\
$\begin{array}{l}\text { 2. It has flexibility to } \\
\text { hybridize with traditional } \\
\text { algorithm. }\end{array}$ & $\begin{array}{l}\text { 2. Due to limited population } \\
\text { size, a genetic algorithm may } \\
\text { sample bad representatives of } \\
\text { good search regions and good } \\
\text { representatives of bad regions. }\end{array}$ \\
$\begin{array}{l}\text { 3. GA is well suited for } \\
\text { parallel computers. } \\
\begin{array}{l}\text { 4. A set of optimum } \\
\text { variables is provided } \\
\text { instead of a single solution. }\end{array}\end{array}$ & $\begin{array}{l}\text { 3. Huge evaluation for } \\
\text { generation and population are }\end{array}$ \\
& \\
\hline
\end{tabular}

local search method which is problem specific, then the overall performance and solution quality can be enhanced. In [5] a review is presented on hybrid genetic algorithm, their effectiveness and efficiency with various techniques. Any local search method can be merged with GA by two ways. In first we can use GA operator to find initial variables for local search and in second we can use local search on initial population and then perform global search using GA. The flow chart of hybrid GA on the basis of first method is described in fig 1 .

GA and its operators are used to find initial population for traditional optimization method. Thus a long trial and error process is avoided which is a drawback of traditional algorithm. This hybrid genetic algorithm is proved to be more effective than traditional algorithms [2].

Space layout planning is one of the most difficult problems in architecture. Three major issues arise regarding this problem [6]

- How to formulate this NP complete problem

- How to find which solution is best based on multiple criteria

- How to control combinatorial nature of generated solution

Designing is very difficult task for human so we are looking for a way to take advantages of search abilities of computer [7]. Space layout planning has to be done on container, warehouse, floor planning and shelves. Container loading problem is example of combinatorial optimization problem. This problem is about to find the best allocation of objects to make efficient use of space of a container.

Warehouse is of two types: conventional warehouse and automated warehouse. The space layout problem in warehouse is to place objects to save the space and to reduce working hours and effort of workers in warehouse. Space layout planning in building floor and shelves is also done to optimize the space and make efficient use of space provided.

\section{LITERATURE REVIEW}

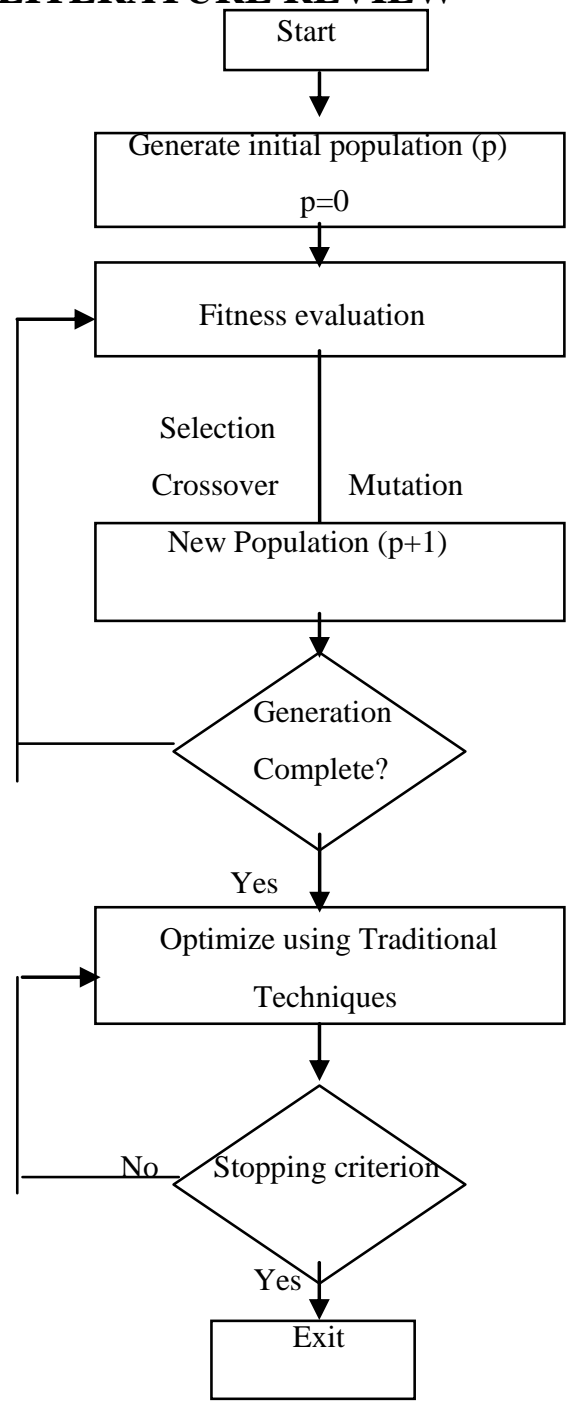

Fig 1: Hybrid GA

Genetic algorithm is an appropriate technique for finding the best solution of space layout problems. In [8] genetic algorithm is used to solve the container storage space allocation problem. Different types of containers (regular, open side, open top, tank, empty and refrigerated) are considered with the objective to determine an optimal container arrangement, which respects customer's delivery deadlines, reduces the re-handle operations of containers and minimizes the stop time of container ship. In [9] three space allocation problems are considered: warehouse, parking slot and crops in land. Genetic algorithm and hill climbing approaches are used to solve these problems. Selected features are weight, temperature, frequency, access and distance. Using these features objective function is created.

There are two types of warehouse layout problems: single level warehouse layout problem in which transportation cost is related to distance between object and main I/O port and multi level warehouse layout problem in which distance has to be measured by considering both horizontal and vertical distance of object and main I/O port. In [10] a two level warehouse problem is solved using genetic algorithm. Efficiency of warehouse depends upon warehouse layout, storage policy and order picking policy. When warehouse is automated then its efficiency is also depends on the high 
power demand. An approach [11] is proposed using genetic algorithm to optimize power peaks.

Architecture layout is NP problem and an important activity in architecture layout planning. This problem can be described as [12]:

- Discover the shapes and size of the components(rooms, walls and other objects)

- Recognize the constraints between these components.

- Finding the related positions of these components to satisfy the constraints between them.

Due to some weaknesses of genetic algorithm (low convergence rate), an improved version is used in [12] to solve architecture layout problem. An extended version of storage space allocation problem in container is solved using GA in [13].

Aisle structure is very important in manufacturing layout. Layout and aisle structure problem has been solved by slicing floorplan in [14]. It is a two stage process. In first stage the cost of material handling is minimized and in second stage aisles are optimized. GA is used for optimization and a comparison is performed between GA and random search (RS) in which GA is proved to be highly efficient than RS to find optimal solution. Shelf space optimization is also an effective field to be concerned. A solution to shelf layout design problem is proposed in [15] using GA.

Hybrid GA (HGA) is an enhanced version of genetic algorithm. In [16] hybrid GA is proposed with particle swarm optimization (PSO) effect for solving combinatorial optimization. Simple GA (SGA) and hybrid GA is compared and the result shows that hybrid GA is better than SGA. Shelf space allocation is also solved in [18] where two objectives are considered and a bi objective model is solved using HGA. In recent researches, fixed shape and fixed size geometric constraints are ignored because a large amount of computation time is needed even for the small problems. To overcome these drawbacks, a shape based block layout approach with unequal area and fixed shape has been proposed in [20]. To find good solution HGA is used. Tabu search (TS) and simulated annealing (SA) algorithms are better than GA in local optimization. So TS and SA were used to search local solution and GA to search global solution. Hybrid GA is scheme where traditional algorithms work with genetic operators. However like GA, HGA has also some weaknesses. HGA does not provide good solution in reasonable computation time, especially in the case of time expensive optimizers like SA and TS. A differential improvement has been proposed in [21] with the aim to improve population individuals in the process of global and local search combination. The layout problem based on multi period planning horizons is solved in [22].

\section{COMPARISON OF DIFFERENT APPROACHES}

Here we study genetic algorithm and hybrid genetic algorithm approach for layout and optimization problems but every idea is different from others. Space layout problem is to find appropriate location for a product which can satisfy all constraints. The comparison between techniques can be done on the basis of:

(a) Problem covered: Different sample models are solved using GA and HGA like warehouse, block layout, shelf space, container etc.

(b) Parameters considered: In each paper, different parameters are considered to maximized or minimized. For example in [10] warehouse problem is solved by objective function which have monthly demand, inventory requirement, horizontal unit transportation, vertical unit transportation, horizontal distance from cell to input port. It means the product will be placed on the basis of above elements. Similarly in [9] warehouse problem is solved using GA with other objectives. Objects will be placed on the basis of environment conditions and distance from obstacles.

(c) Approaches: In this paper, only genetic algorithm and hybrid genetic algorithm are considered.

(d) Results: Result of every experiment improves the solution quality of space layout and planning problems.

A comparison of 12 papers has been done in Table 2. It will be valuable for those who want to solve space layout problems by making improvements in GA.

\section{CONCLUSION}

In this study, we review the performance of GA and HGA for solving space layout problems. These two approaches become useful when the problem size is varied and ill defined.

GA and HGA are proved to be effective for space layout and optimization problems. Designing becomes very difficult with large data so we have to use the ability of computer in designing. GA is a soft computing technique like neural network and fuzzy system which is used to enable computer with human like thinking capability. Twelve techniques are compared in this paper so that reader can differentiate the solution. Several results can be concluded from this study:

1. Majority of work has been done in genetic algorithm.

2. Genetic and hybrid genetic algorithm both have some weaknesses so an improvement is needed for high quality solution.

3. Different sample can be solved using GA and HGA. 
Table: 2 Comparison of approaches

\begin{tabular}{|c|c|c|c|c|}
\hline References & Problem Covered & Parameters considered & Approaches & Result \\
\hline $\begin{array}{l}\text { 1.Dragan, Vlandimir, } \\
\text { Aleksandar, Zorica } \\
\text { (2011) }\end{array}$ & $\begin{array}{l}\text { Multiple warehouse } \\
\text { layout }\end{array}$ & $\begin{array}{l}\text { Monthly demand, inventory } \\
\text { requirement, horizontal unit } \\
\text { transportation, vertical unit } \\
\text { transportation, horizontal distance from } \\
\text { cell to input port }\end{array}$ & Genetic algorithm & $\begin{array}{l}\text { GA has proved to be } \\
\text { successful with } \\
\text { concept of fine grained } \\
\text { tournament selection } \\
\text { (FGTS) and frozen } \\
\text { bits. }\end{array}$ \\
\hline $\begin{array}{l}\text { 2. Rafael and Christian } \\
\text { (2010) }\end{array}$ & $\begin{array}{l}\text { Warehouse, Car parking, } \\
\text { Land of cultivation }\end{array}$ & $\begin{array}{l}\text { Environment property (Weight, } \\
\text { Temperature, Frequency, Access, } \\
\text { Distance) }\end{array}$ & $\begin{array}{l}\text { Genetic algorithm and } \\
\text { Hill climbing }\end{array}$ & $\begin{array}{l}\text { GA has better } \\
\text { performance than HC } \\
\text { and Random search. }\end{array}$ \\
\hline $\begin{array}{l}\text { 3.Ayachi, Kammarti, } \\
\text { Ksourl, Borne (2010) }\end{array}$ & $\begin{array}{l}\text { Container storage space } \\
\text { allocation }\end{array}$ & $\begin{array}{l}\text { Delivery time of product and minimum } \\
\text { no. of objects re handles to unload the } \\
\text { container, types of container }\end{array}$ & Genetic algorithm & $\begin{array}{l}\text { GA is compared with } \\
\text { LIFO and GA } \\
\text { performs better when } \\
\text { problem size } \\
\text { increases. }\end{array}$ \\
\hline $\begin{array}{l}\text { 5. Siripong Malasri } \\
\text { and Pili Segui (2011) }\end{array}$ & Shelf space optimization & Shelf length and box availability & Genetic algorithm & \\
\hline $\begin{array}{l}\text { 6. Cardenas, Gareia, } \\
\text { Romeral, and Andrade } \\
(2009)\end{array}$ & $\begin{array}{l}\text { Power peaks in } \\
\text { automated warehouse }\end{array}$ & $\begin{array}{l}\text { Number of ASR, Max power peaks and } \\
\text { load profile of ASR (Automated Storage } \\
\text { Retrieval system ) }\end{array}$ & Genetic algorithm & $\begin{array}{l}\text { significant results with } \\
\text { reduction of maxim } \\
\text { power demand }\end{array}$ \\
\hline $\begin{array}{l}\text { 7. Liang, Lee and } \\
\text { Huang (2007) }\end{array}$ & $\begin{array}{l}\text { Container loading } \\
\text { problem }\end{array}$ & $\begin{array}{l}\text { Number of containers, volume of } \\
\text { container, object quantity and objet } \\
\text { volume }\end{array}$ & $\begin{array}{l}\text { Hybrid approach of } \\
\text { genetic algorithm and } \\
\text { ant colony algorithm }\end{array}$ & $\begin{array}{l}\text { Approach is generally } \\
\text { better than others with } \\
\text { some weaknesses. }\end{array}$ \\
\hline $\begin{array}{l}\text { 8. Cunli Liang, Yiu } \\
\text { Ming Chengu and } \\
\text { Yuping Wang (2007) }\end{array}$ & Shelf space allocation & $\begin{array}{l}\text { Maximize the total profit of product and } \\
\text { minimize total time to sale the store's } \\
\text { product }\end{array}$ & $\begin{array}{l}\text { Hybrid Genetic } \\
\text { Algorithm }\end{array}$ & $\begin{array}{l}\text { A bi-objective model } \\
\text { is transformed into } \\
\text { single objective model } \\
\text { and HGA outperforms } \\
\text { Yang's model. }\end{array}$ \\
\hline $\begin{array}{l}\text { 10. M. H. Mehta } \\
\text { (2012) }\end{array}$ & $\begin{array}{l}\text { Combinatorial } \\
\text { optimization }\end{array}$ & $\begin{array}{l}\text { Previously calculated population is } \\
\text { compared to the next population }\end{array}$ & $\begin{array}{l}\text { Hybrid Approach of } \\
\text { Genetic Algorithm and } \\
\text { Particle Swarm } \\
\text { Optimization }\end{array}$ & $\begin{array}{l}\text { SGA and HGA is } \\
\text { compared and HGA } \\
\text { performs far better } \\
\text { than SGA. }\end{array}$ \\
\hline $\begin{array}{l}\text { 11. Y. Wu and E. } \\
\text { Appleton (2002) }\end{array}$ & $\begin{array}{l}\text { Block layout and aisle } \\
\text { structure }\end{array}$ & $\begin{array}{l}\text { Flow density and shortest aisle distance } \\
\text { from one department to another, area of } \\
\text { floor and area of department }\end{array}$ & Genetic Algorithm & \\
\hline $\begin{array}{l}\text { 12. Young Hae Lee, } \\
\text { Moon Hwan Lee } \\
\text { (2002) }\end{array}$ & $\begin{array}{l}\text { A shape based block } \\
\text { layout approach to } \\
\text { facility layout problem }\end{array}$ & $\begin{array}{l}\text { Material handling cost and slack area } \\
\text { cost }\end{array}$ & $\begin{array}{l}\text { Hybrid Genetic } \\
\text { Algorithm }\end{array}$ & $\begin{array}{l}\text { SA and TS are used } \\
\text { with GA and has better } \\
\text { performance than } \\
\text { simple GA with some } \\
\text { limitations. }\end{array}$ \\
\hline
\end{tabular}




\section{REFERENCES}

[1] Randy L. Haupt, Sue Ellen Haupt, 2004 "Practical Genetic Algorithms," second edition, Willy Interscience, a John Willy and sons , INC., Publications, pp. 18-24.

[2] Pengfei Guo, Xuezhi Wang, Yingshi Han, 2010 "The Enhanced Genetic Algorithms for Optimisation Design", 3rd International Conference on Biomedical Engineering and Informatics, IEEE,

[3] Melanie Mitchell, 1995 "Genetic Algorithms: An Overview", Adapted from an Introduction to Genetic Algorithms, Chapter 1. MIT Press,

[4] David Beasley, David R. Bully, Ralph R. Martin, "An overview on genetic algorithms: Part 1, Fundamental",

[5] Tarek A. El-Mihoub, Adrian A. Hopgood, Lars Nolle, Alan Battersby, 2006 "Hybrid Genetic Algorithm: A Review”, Engineering Letters.

[6] Jun H. Jo and John S. Gero, 1998 "Space layout planning using an evolutionary approach", Artificial Intelligence in Engineering 12(3), pp 149-162.

[7] Siripong Malasri and Pili Segui, 2011 "Shelf Space Optimization using a Genetic Algorithm”, MAESC 2011 Conference, May 3, Christian Brothers University, Memphis, Tennessee.

[8] I. Ayachi, R. Kammarti, M. Ksouri and P. Borne, 2010 "A Genetic algorithm to solve container storage space allocation problem", International conference on Computational Intelligence and Vehicular System, IEEE,

[9] Rafael E. García Q., Christian G. Quintero M., Ph. D., 2010 "Space Allocation using Intelligent Optimization Techniques" IEEE

[10] Dragan Matic, Vladimir Filipovic, Aleksander Savic, Zorica Stanimirovic, 2011 "A Genetic algorithm for solving multiple warehouse layout problem", Kragujevac Journal of Mathematics, vol 35 Number 1, pp. 119-138.

[11] J. J. Cárdenas, A. Garcia, J. L. Romeral, F. Andrade, 2009 "A Genetic Algorithm Approach to Optimization of Power Peaks in an Automated Warehouse", IEEE.

[12] Romualdas Bausys, Ina Pankrasovaite, "Optimization of architectural layout by the improved genetic algorithm",
Journal of civil engineering and management, vol. 11, no. 1, pp. 13-21.

[13] Mohammad Bazzazi, Nima Safaei, Nikbakhsh Javadian, 2009 "A genetic algorithm to solve the storage space allocation problem in a container terminal", Computer and Industrial Engineering, pp. 44-52.

[14] Y. Wu, E. Appleton, 2002 "The optimization of block layout and aisle structure by a genetic algorithm" Computer and industrial engineering, vol. 41, issue 4, pp. $355-472$

[15] Hark Hwang, Bum Choi b, Grimi Lee, 2009 "A genetic algorithm approach to an integrated problem of shelf space design and item allocation" Computer and industrial engineering 56, pp. 809-820.

[16] Kamlesh Dutta, Siddhant Sarthak, "Architectural space planning using evolutionary computing approaches: a review",

[17] M. H. Mehta, 2012 "Hybrid Genetic Algorithm with PSO Effect for Combinatorial Optimisation Problems",International Journal of Advanced Computer Research, Vol 2,Number 4, Issue-6

[18] Cunli Liang, Yiu-ming Cheung and Yuping Wang, 2007 "A Bi-Objective Model for Shelf Space Allocation Using a Hybrid Genetic Algorithm", Proceedings of International Joint Conference on Neural Networks.

[19] Shyi-Ching Liang, Chi-Yu Lee, Shih-Wei Huang, 2007 "A Hybrid Meta-heuristic for the Container Loading Problem", Communications of the IIMA, Vol 7 Issue 4

[20] Young Hae Lee, Moon Hwan Lee, 2002 "A shape based block layout approach to facility layout problems using hybrid genetic algorithm", Computer and Industrial Engineering, vol 42, pp. 237-248.

[21] Zvi Drezner, Alfonsas Misevic ius, 2012 "Enhancing the performance of hybrid genetic algorithms by differential improvement", Computers \& Operations Research, vol. 40, pp. $1038-1046$

[22] Amir Sadrzadeh, 2012 "A genetic algorithm with the heuristic procedure to solve multi-line layout problem", Computers \& Industrial Engineering, vol. 62, pp. 10551064. 